\title{
A ALQUIMIA DO SANGUE E DO RESGATE EM LEVANTADO DO CHÄO,
}

\author{
Renato Cordeiro Gomes
}

\begin{abstract}
Para Cleonice Berardinelli e Jorge Fernandes da Silveira

o mundo de hoje não pode ser descrito aos homens de hoje a não ser que lhes seja apresentado como transformável.
\end{abstract}

BERTOLT BRECHT

O texto lido por José Saramago na entrega do Prêmio D. Dinis - 1986 a ele conferido pelo romance $\mathbf{O}$ ano da morte de Ricardo Reis, é uma profissão de fé. E como sujeitu-trabalhador que declara: «Tenho a minha jeira e a minha enxada no campo da cultura, (...) os pés plantados na fértil terra da lingua que falo e em que escrevo». E com a parte que lhe cabe deste latifúndio verbal - bem comum que ele transforma a palavra em ação. Aceita a boa peleja, para, com a posse das palavras, «coração da ação», colocar os saberes em circulação e em xeque, para ai trabalhar os materiais da vida.

E neste caminho que constrói os seus textos «em viagem» que se adentram no corpo da cultura, para aí instaurar sua intervençăo, a exemplo de Levantado do chäo (1980), que recebeu o Prêmio Cidade de Lisboa - 1981.

\section{UMA NARRATIVA TECIDA}

Levantado no chảo è uma narrativa tecida, articulada por vários fios extraidos de outros textos. Reboam ai vozes de mil bocas. 0 enleio do texto vem do fato de não se resignar a um só fio; seu enredamento vem do fato de que uma história é feita de muitas histórias. E a atitude que nega a concepção do texto regido por uma voz monológica centrada no autoritarismo do narrador.

Deste modo, constata-se a recusa em projetar o mundo ficcional e a História, a partir de uma consciência individual única. Esgarça-se o principio de causalidade, base do enredo linear, realizado numa estrutura fechada que se dá pelo rigoroso encadeamento lógico de motivos e situaçōes.

A obra «é. uma conversa misturada, ora diz um, ora diz outro», que se tece pelo lado direito (latifúndio, Estado, Igreja), o lado da continuidade do brilho dos nomes em - berto (o lado que se quer destecido); e pelo lado avesso, o lado dos camponeses, a gente «solta e miúda, que veio com a terra, embora não registrada na estrutura, 
almas mortas, ou ainda vivas?». Os dois lados tramam-se, à medida que também se tece o dia «levantando e principal»: o sim que nega e o não que afirma, o dia tecido na História e na estória - 025 de abril, o fato e a metáfora - o terceiro lado entretecido como a «luz-balão» do «Tecendo a manhã» de João Cabral, que plana livre de armaçāo.

Deste modo, a fala plural resgata pela alquimia do verbo as vozes caladas e recalcadas. 0 narrador principal deixa cruzar na superfície textual outros falantes que se tornam sujeitos à medida que adquirem seu próprio discurso com o despertar da consciência, quando não são mais repetidores passivos e submissos de discursos alheios. Esses novos discursos se entretendem, se cruzam como gritos de galo, individualidades que constroem a manhã coletiva, realizada após a viagem de três quartos de século, na História de Portugal e do latifúndio alentejano, com a saga ficcional dos Mau-Tempos.

A História e a sociedade são lidas pelo escritor como textos em que ele se inscreve ao reescrevê-los. A História é lida em seus claros, naquilo que foi calado pela história oficial que aparece em contraponto (cf. os acontecimentos como a República, as duas Grandes Guerras, Salazar, o episódio Delgado, o 25 de Abril, etc.) O narrador preenche os desvãos, os silêncios, os ocos da História.

Este narrador aparentemente olimpico, a principio, parece ser o «mandador das falas», como se o «livro do latifúndio» fosse escrito por apenas um sujeito autoritário. Mas é lendo este mesmo livro que o narrador vê $o$ avesso e aprende com o outro. Vai-se estabelecendo a troca, o diálogo. Aprendizagem de mäo dupla. Para melhor narrar - latifúndio, o narrador tem de aprender a linguagem do próprio latifúndio e, num diálogo generoso, permitir a aprendizagem do outro que, aos poucos, adquire voz. Os donos do latifúndio eram também os donos da voz, como aparentemente o narrador, dono da escrita aquele que a assina. A voz conquistada por personagens, como João e Antônio Mau-Tempo, Manuel Espada, Gracinda, Sigismundo Canastra, Maria Adelaide... faz deles sujeitos da História. Neste sentido, exemplarmente, Antônio Mau-Tempo torna-se «mandador das falas».

Assim, a palavra múltipla e dialógica acompanha o processo de transformação social, e tece o texto na tensão entre lissa e urdidura, no cruzamento de vários discursos. O latifúndio é um mar de palavras - ditas, entreditas, sugeridas ou caladas. Falam por eles e com ele os «contentes»: o padre Agamedes, os feitores e capatazes, D. Clemência, a guarda, a Pide, os Bertos... Falam contra ele os trabalhadores na sua hora e na sua vez, e o narrador. $O$ autor, como sujeito da escrita, quer configurar, pela palavra que é ação, o país possivel na liberdade, 0 pais «levantado do chão», produto desse chão que é terra fértil - na tensão, na expansão outra (na terra, não no mar), na metáfora, na escrita - «ação desencadeada pela nomeação de Abril e de Cravo», que possibilita a contra-imagem de ressurreição, «o dia levantado e principal» que não está na consumaçāo dos séculos, mas aqui e agora, no reino deste mundo. 
O relato ficcional acompanha, em tensāo, a história portuguesa. Trabalha o patrimônio histórico, «riqueza comum, não repartivel em propriedade pessoal», como trabalha a terra fértil, latifúndio verbal, também patrimônio comum. Ambos - história e língua - não podem deixar de ser reflexo, «mesmo que apenas mediato, das tensōes e oposiçōes inseparáveis duma sociedade viva», como atesta o próprio autor.

Assim, Levantado do chão intervém numa sociedade, não apenas construindo dela um retrato, ou um painel estático. A narrativa move-se, mobiliza-se, mobilizando autor, narrador e personagens, nāo apenas como sujeitos do enunciado, mas também como sujeitos da enunciaçăo que se torna enunciada. O narrador, como sujeito privilegiado da enunciação, pōe a nu a sua construção como produçăo.

Lê-se, no final do primeiro capitulo: «(...) ai está a terra e quem há de trabalhar, crescei e multiplicai-vos. Crescei e multiplicai-me, diz o latifúndio. Mas tudo isto pode ser contado de outra maneiras.

Depois de apresentar a paisagem (natureza), o narrador a insere na cultura. A terra que aí. está, não é apenas o latifúndio, mas também o seu livro, ou melhor, este livro que lemos. Quem trabalha - latifúndio (terra e livro) são os camponeses, o narrador e 0 autor. «Crescei e multiplicai-me» é a voz do latifúndio que se concretiza na enunciação: proliferam os narradores e suas histórias. O longo livro do latifúndio pode ser contado de diversas maneiras, estendendo-se numa «grande biblioteca». O latifúndio é um mar de histórias; histórias que compōem o seu livro e que requerem outros contares.

0 relato enquanto produção de vida realiza-se na tensão entre - contar e o criar. Recusa a reprodução puramente mimética da realidade efetiva pré-textual: rejeita o primado do documental. $O$ autor implícito é também um leitor qualificado que lê a realidade, lê os saberes, nessa leitura (a narrativa de Levantado do chão) que já implica uma construçāo, através da transgressāo; «a palavra como capacidade de movimentos.

\section{REPETIÇAO E INVENÇAO}

O documental, a crônica, se tece com e pelo ficcional, pela tensão da palavra metafórica que instaura a realidade enquanto escrita, enquanto invenção, cujos processos se acham explicitados.

A narrativa é, nesta ótica, «um longo falar, assim como um juntar de pedras de calçada ou de ponte, melhor será de ponte, pois sobre ela hão.de passar os anos, os passos, os carregos, e por baixo é um abismo». «Tudo vai da palavra e da ênfase dela», como a conversa de Sigismundo Canastro e João Mau-Tempo. 0 «longo falans é como o olhar do milhano que «abrange o próximo e o distante, isto e aquilo, o latifúndio excessivo e a paciência na sua justa medida». O «longo falan» excessivo é como o mar, a massa líquida em sua adição infinita, que articula todas as histórias atraves. 
sadas pela ponte-fala do narrador e pelo leitor, o «longo-falap» é a atitude do narrador (que chama o leitor para o mesmo entendimento), para compensar o «falar tão pouco que é o de todos os dias», porque conhece as dificuldades da escolha da palavra exata e a sua serventia.

Se a narrativa se constrói pelo repetir à exaustāo, cumpre perguntar qual o lugar da invenção? Diz o narrador: «Seria preciso muita imaginação para inventar acontecimentos extraordinários. Este viver é feito de palavras repetidas e de repetidos gestos» «(...) é tudo a mesma história, não tenho é tempo para contars. Mas é no repetir que está 0 inventar. Pela atitude do narrador principal, que é o grande administrador de falas, de discursos; as repetiçőes se dão em diferença: a repetiçāo esgota, de certa maneira, o conceitual que, transgredido se torna metáfora - lugar da invençāo. «Quem em tudo isto não encontrar novidade precisa que lhe tirem as escamas dos olhos», pois «olhar, que é sinal de descobrin». «Além disso, note-se, a história repete-se muito», mas «pode o falar ser o mesmo, ou sendo sim o mesmo é o entender que é diferente».

Se «a história das searas repete-se com notável constância, mas tem suas variantes» que «mereceriam um falar mais extenso, um dizer sem pressas», e o narrador rejeita esse proceder, compete ao leitor, com o olhar de descobrir, desvelar suplementarmente essas variantes e perceber o jogo metafórico que semantiza «os olhos azuis», emble. maticamente a submissāo e o resgate; o «cão e a perdiz», a resistência e a uniäo; a «lebre», a curiosidade do saber, a busca de informação; o «milhano» que vê da distância e que solta o grito de liberdade e levanta mais alto vóo; as «formigas» que levantam, unidas, as cabeças para a luta; a cena da fonte; o cravo e o 25 de Abril - 0 vôo que se celebra: a revolução. Essas imagens metaforizadas na sintaxe do texto desembocam no latifúndio, «o mar interion», - lugar da metáfora. As comparaçōes com o mar «tanto servem como servem pouco, dizer que o latifúndio é um mar, mas terá razão de fácil entendimento, se esta água agitarmos, toda a outra em redor se move, às vezes de tảo longe que os olhos o negam, por isso chamariamos enganadamente pântano a este mar, e que o fosse, muito enganado vive quem de aparências se fia, sejam elas de morte».

No percurso do texto, as repetiçōes dão-se em diferença: «Todos os dias são iguais e nenhum se parece». O ritmo regular da natureza, como a história naturalizada pelos dominadores, - repetiçőes, portanto, transforma-se por força da reação em cadeia, na outra «linguagem guerreira». O latifúndio é historicizado: o corpo do latifúndio é histórico. Em Levantado do chảo, «juntam-se todos com todos». Ainda que o narrador não abra mão de seu lugar de mestre, nem da mensagem ideológica forte (a Revolução), nem de sua pedagogia, desloca a linguagem citadina para um discurso rural e dissolve a sua voz de narrador autoritário, abrindo-se para a democracia da linguagem. 
Com esses deslocamentos, no mar deste latifúndio que é o romance, circulam como ondas os diversos saberes - dos ditados populares e suas transformaçōes ( «Em abril, falas mil»), passando pelas imagens bíblicas, pelas citações históricas e literárias, à pedagogia da revolução. Com esse processo, o autor esgota e ultrapassa - modelo da narrativa neo-realista, leva-o à exaustão. Saramago, «sem abdicar do compromisso com o seu tempo, investe na autonomia da escrita; sabe que, ao invés de uma relação especular com a realidade, há no texto a ocupação de um espaço de diferenças, pois cada autor operacionaliza os instrumentos do mundo nos extremos da sua própria linguagem», como aponta Jorge Fernandes da Silveira.

Porque tece a Revolução nas malhas da invenção do seu texto, que é descobrir e revelar, crispando as palavras de aço na forja da escrita, realiza no presente «o livro futuro» (de que falava Carlos de Oliveira), reelaborando, por deslocamento, a História e o passado com seus saberes instituidos. Este processo está condicionado pelo «latifúndio narrativo» que agudiza os procedimentos ficcionais: «são suposiçōes de quem procura a realidade». «São casos verdadeiros, estes, por isso custam tanto a crer a quem se pauta por ficçōes».

No jogo realidade/ficção, o narrador assume o prazer de narrar, pois sabe que «não existiriam as histórias se nāo existisse quem as conta»: sabe que o melhor dos homens «é a vida contada ou por contan». Assim, «pôde o narrador dizer quanto queria, é o seu privilégio». Privilégio de ser como a lebre da fábula contada por Antônio Mau-Tempo (outro contador sedutor), mas que não morre pela sua curiosidade de ler o jornal do mundo, o cotidiano do latifúndio. Privilégio de ser como o milhano que do alto do seu vôo a tudo vê; com suas artes e manhas, sem as mazelas de miopia e astigmatismo (palavras da cidade), vê perto e vê longe, com a consciência do seu contar. «São coisas sabidas do narrador, além de outras que não vêm para o caso, pois esta história é de latifúndio e não de cidadess: jeira, enxada, terra fértil!

\section{LEVANTAMENTO DOS NOMES}

Ousemos uma metáfora, aproximando Levantado do chão a um «livro de linhagem», aquele que traça a genealogia das familias nobres. Aqui, porém, o narrador, além de levantar a origem e a herança dos «herdeiros» - os Horques, volta-se para outro núcleo de personagens, os Mau-Tempos, os deserdados sem terra. Estabelece, assim, dois paradigmas antitéticos, em que se articulam «os bens e o sangue».

Os Horques têm seus nomes registrados na escritura, junta. mente com as «santíssimas propriedades que de longe vêm», o latifúndio que lhes dá «um poder que thes vem dos avós dos avós». «São os donos da terra e de quem trabalha nela». Cabe ao narrador, em sua estratégia narrativa, recuperar este passado já sabido e inscrito na memória do latifúndio desde Lamberto, a origem. 
Os Mau-Tempos são a gente «solta e miúda que veio com a terra, embora não registrada na escritura»; os «miseráveis que toda a vida deles e dos pais e dos avós e dos pais dos avós tiveram fome». Deserdados desde a origem, são uma familia sem linhagem e sem história, condição transmitida pela viagem do sangue. Sem propriedade que os inscreva na História, nada possuem, a näo ser a força de trabalho. São herdeiros «de não mais que petrechos de trabalho se não se gastaram ou partiram antes, como partido e gasto vou eu (o homem do latifúndio) estando». Cabe ao narrador levantar do chão a história dessa familia e inscrevê-la no livro do latifúndio. «Todas as familias têm as suas fábulas, algumas nem isso sabem, como esta dos Mau-Tempos, que bem a podem agradecer ao narradon, que estabelece a genealogia dessa gente, perseguindo a longa peregrinação dos «olhos azuis». No novo livro de linhagem, há lugar para os despossuidos, resgatados para a História, através da alquimia do sangue e do verbo.

Nestes dois paradigmas, a questão do espaço é uma das invariantes possiveis para articulá.los. E a paisagem descrita no primeiro capítulo, à maneira bíblica, que permite, em primeira instância, caracterizar os personagens. De um lado, os que têm um espaço próprio, a propriedade, de onde advém todo o poder e todos os direitos, na sua regularidade. De outro, aqueles a quem são negados todos os direitos; os que não tèm espaço próprio; é o que «pode andar por cá uma vida toda e nunca se achar, se nasceu perdido». De um lado, os que sāo servidos; de outro, os que servem.

Os primeiros são definidos pelos componentes miticos. 0 traço de dominação e poder localiza-se na origem, miticamente natural. A dinastia dos Horques começa com Lamberto, «senhor da povoação e seu termo (...), com franqueza e liberdade de tributo», que recebe de D. Joäo 1 o encargo de cuidar da terra, povoá-la e regê-la.

A narrativa fixa, neste ponto, um conjunto de ações que ocupa um tempo remoto, como se fosse um tempo sagrado. Explora-se a origem in illo tempore, um tempo em que algo se tem pela primeira vez. E o tempo da fundação de uma ordem, a partir da ocupação e da posse do latifúndio de Monte Lavre.

Tem-se, assim, a atualização de um primeiro tempo, através da fala do narrador e do próprio Lamberto. A narração funciona como um rito reatualizador desse tempo primeiro, através da sucessāo dos nomes em -berto que se transmitem em contigüidade e aproximam-se do «herói fundadon». Os nomes que se vão intercambiando e se confundindo na narrativa, revelam o desejo de reintegrar a situação primordial. Essa naturalizaçāo, através do mito, responde aos mecanismos do poder que se quer perpétuo: sempre foi assim, e assim deve ser até a consumação dos séculos. Miticamente, teologicamente, a origem deveria coincidir com o fim. Mas é o que o romance desconstrói, historicizando o que se pretendia mítico e mostrando a condição passageira de uma dada situação histórica. Fixa não como o 106 
mundo é, mas como ele se torna: o homem em processo, objeto de pesquisa. 0 mundo é tal de maneira que possa ser outro - como nos ensina a lição de Brecht.

Voltemos aos nomes da dinastia dos Horques, mencionados em cadeia, biblicamente, compondo «outras monarquias»: de Lamberto nasceu Dagoberto, de Dagoberto nasceu Alberto, de Alberto nasceu Floriberto, e depois veio Norberto, Berto e Sigisberto, e Adalberto e Angilberto, Gilberto, Ansberto, Contraberto, que admiraçāo é essa terem tão parecidos nomes, é o mesmo que dizer latifúndio e dono dele...»). A propriedade, os direitos e o poder transmitem-se pelo e no contínuo do nome, marcado pelo radical germânico bert (da origem alemã da familia) que significa brilho. 0 brilho encoberto no nome paträo.

Este brilho, a luz do poder, epicentro do latifúndio, opōe-se à lama do sobrenome Mau-Tempo que tem uma carga semântica suplementar com a caminhada na chuva que marca sua entrada em cena.

o retorno à origem dessa familia, cujo percurso é assinalado pelo leit-motiv emblemático dos (ôhos azuis», permite ao narrador reconstruir a linhagem dos Mau-Tempos, na descontinuidade que a caracteriza.

Essa origem cruza-se miticamente no tempo primordial dos Horques Alemães. Relatando a estranheza dos olhos azuis de João Mau-Tempo, remonta o narrador à cena da fonte de Amieiro, quase quinhentos anos antes, em que um daqueles estrangeiros que viera com Lamberto Horques Alemão, «um galhardo homem de pele branca e olhos azuis» forçou uma donzela. Acrescenta o narrador: «Assim, durante quatro séculos estes olhos azuis vindo da Germânia apareceram e desapareceram, tal como os cometas que se perderam no caminho e regressam quando com eles já se não conta, ou simplesmente porque ninguém cuidou de registrar as passagens e descobrir a sua regularidadess.

Os olhos azuis, marca da submissão e da bastardia, aponta a origem dos deserdados. Sem bens, a herança transmite-se pelo sangue: é o sangue! Se a regularidade passada se perdeu no tempo, sem registro (ao contrário da linhagem dos Bertos), o narrador a recupera no presente: de João a Maria Adelaide. A luz desses olhos encoberta pelo nome dos Mau-Tempos (sem luz, sem brilho) é historicizada na tenacidade da luta de João contra o latifúndio, contra a submissão inscrita no sangue desde a origem como um destino inexorável; e na celebração de Maria Adelaide no dia da Revolução.

Para Maria Adelaide, cujo nome registra o mesmo radical de Adalberto (Adelaide - a de linhagem nobre; garbo distinto, fidalgo), convergem todos os significados dos nomes em -berto: brilhante em sua própria terra (Lamberto); nascido em dia esplendente, brilhante como o dia (Dagoberto); brilho da nobreza (Adalberto e a variante Alberto); flor brilhante (Floriberto); brilhante do norte (Norberto); luzente, resplandencente (Berto); brilhante como a vitória (Sigisberto); anjo reluzente (Angilberto); prisioneiro de guerra ilustre (Gilberto); 
brilho dos deuses (Ansberto); brilho contrário (Contraberto). Enfim, o brilho encoberto revelado pelo 25 de abril, a luz do «dia levantando e principal», a luz que se tem de saber o que é, «como se tivesse vivido sempre com os olhos fechados a agora, enfim, os tivesse abrido».

Maria Adelaide que é Mau-Tempo nos olhos azuis (na origem) e Espada no nome (Cf. «Que farei eu com esta espada? Ergueste-a, e fez-se»s. Fernando Pessoa. O Conde D. Henrique. Mensagem), é também metáfora da Revolução, o começo voluntário, «símbolo fecundo» que «vem na Aurora Ansiosa». (Cf.: Fernando Pessoa. O Encoberto).

Levantado do chão é a história «de quem cá ficou e não dos que foram emboras. E o assentamento da linhagem dos Mau-Tempo e da gente miúda como eles, marinheiros às avessas, que não tinham quem os apadrinhasse e levantasse os seus feitos pela «restauração da pátria»s. Este será o papel do narrador e do autor que os assinala nesta viagem outra, no mar interior do latifúndio. Realmente, a História pode ser contada/escrita de outra maneira.

Sem a grandiloqüência épica, a narrativa volta.se, em sua oralidade, não mais para os heróis da história oficial, não mais para «as armas $e$ os barões assinalados», mas para o (anti) - herói sem rosto e sem voz. Saramago, com sua escrita, dá vida a esses «heróis», nomeando.os e fazendo.os conquistar sua (deles) própria escrita e voz. Mostra que «é um perigo isto de escrever e falan». Mas melhor que tudo é aquilo, a formosura dos nomes nasce da violentação doutros anteriores ou de palavras ditas sem intençăo de nome virem a ser...

Esses «heróis» dos novos tempos violentaram outros nomes anteriores e tornaram-se exemplarmente também gente portuguesa - a que constrói o presente afastando.se da necrofilia do passado. Dançam sobre a tumba do fascismo, com a alegria dos que nảo sabiam e descobriram. Não novos mundos, para dilatar a Fé e o Império, mas para a retomada da terra, para construir uma casa habitável, através da ação, da ação da palavra que resgata a alquimia do sangue, 0 cabedal dos deserdados. Na fonte outra, o Encoberto sai do nevoeiro, metaforizado no 25 de Abril. E a hora do dia levantado e principal. Hora de possiveis bons-tempos: não mais histórias de maus-tempos?

\section{NOTAS}

1. O título deste trabalho foi tomado do «Sonetos, quinto poema de eAssombraçåo», de Carlos de Oliveira - Poeslas (1945-1960). Lisboa, Portugália, [1962].

2. Os trechos entre aspas, sem outra indicação, são de José Saramago Levantado do chão. Såo Paulo, Difel, 1982. 
3. O texto lido por Saramago na entrega do Prèmio D. Dinis - 1986, intitula-se aO poder deve deixar-se molhars, publicado no Jornal de Letras, Lisboa, 28 jul, a 3 ago. 1986.

4. Inspiraram mais diretamente este trabalho os seguintes textos:

COUTADA, Leticia M. Machado. Levantado do chåo. José Saramago, escrita, história, reescritura. Rio de Janeiro, PUC-RJ, 1983. Memeo.

LEPECKI, Maria Lúcia. a Levantado do chåo: história e pedagogias. Lisboa, Jomal de Letras, 27 out. a 9 nov. 1981.

SILVEIRA, Jorge Fernandes da. Notas de aula do curso de Literatura Portuguesa: A mais estrangeira das literatura. Pós-graduaçăo, PUC.RJ, $2^{\circ}$ semestre 1986. 